(c) 2003 Elsevier B.V. All rights reserved.

\title{
Density estimator for strip transects when animals show directional movement and observation speed is slow
}

\author{
Verena M. Trenkel ${ }^{1, *}$ \\ ${ }^{1}$ Laboratoire Maerha, Ifremer, Rue de l'lle d'Yeu, BP 21105, 44311, Nantes, cedex 3, France \\ *: Corresponding author : V. Trenkel, Tel.: +33-240274053; fax: +33-240374075, email address : \\ Verena.Trenkel@ifremer.fr
}

\begin{abstract}
:
A strip transect population density estimator and its variance are presented. These take into account stochastic survey velocity as well as stochastic swimming velocity and non-random swimming direction of the surveyed animals. The estimator is mainly of interest for surveys of animals with a directional swimming behaviour and swimming velocities similar to the survey velocity, such as those carried out by divers or remotely operated vehicles.
\end{abstract}

Keywords: Visual transects; Fish movement; Bias; Abundance estimation; Variance estimators 


\section{Introduction}

Visual strip transects are a common method for estimating population densities in the marine and aquatic environment (Buckland et al. 2001; Seber 1982). The underlying idea is to instantaneously evaluate the number of individuals in a strip of known length and width. Strip transects are often used for estimating fish densities. Scuba divers carry out the task of counting in coastal zones, on coral reefs and in lakes (e.g. Dufour et al. 1995). In deeper or less accessible areas divers can be replaced by remotely operated vehicles (ROV), which are diving robots equipped with video cameras. In the later case counting is then carried out from videos. Both methods have in common that fish swimming speed can be fast with respect to surveying speed which leads to bias in abundance estimates if fish swimming direction is not random due to the survey area being different from the area covered on the ground (Watson et al. 1995). In the case of fish, certain species might systematically swim against the current or on the contrary drift with the current. The same problem can occur than surveying fast flying sea birds from survey vessels.

Estimation bias is maximal when fish move against or in the same direction as the survey and zero when they move at right angle (Watson et al. 1995). In the case of directional movement towards the surveyor or the ROV, bias becomes important ( $>25 \%$ standard error) when fish velocity (swimming velocity - current velocity) is around a third of the surveying velocity and increases linearly with fish velocity (Watson and Quinn II 1997). There are two ways of avoiding estimation bias: increase surveying speed or survey at right angle to fish swimming direction. However, for operational reasons it might be impossible to do either. For divers, surveying speed is limited by the time it takes to swim along the transect and to note the encountered animals. For ROVs, surveying speed has to be slow enough so that fish can be identified on the videos. Due to safety or time constraints it might be impossible to carry out all transects at right angle to the fish swimming direction.

In this paper a population density estimator is presented that includes fish swimming velocity, approach angle and surveying velocity. Appropriate variance estimators are derived. The method is demonstrated for the glacial eelpout, Lycodes frigidus, a deep-sea species, which was surveyed using an ROV.

\section{Estimators}

Assuming the survey progresses at velocity $S$, strip length is $L$ and animals are always counted when they cross a line of width $w$, which is perpendicular to the survey direction, the survey area on the ground is $w L$ (black area on Figure 1a). If animals move non-randomly with velocity $F$ and are encountered with an approach angle $\theta$ other than $90^{\circ}$ or $270^{\circ}$, the effective survey area is different from the survey area on the ground as the strip length is modified by the fish velocity component parallel to the survey direction (black plus grey area on Figure 1a). The resulting effective strip length is $L^{*}=\frac{L}{S}(S-F \cos \theta)$ (Watson et al. 1995) given $F \cos \theta \leq S$. In the case where the parallel fish velocity component is superior to the survey velocity, absolute differences need to be taken. The effective survey area is then given by

$$
a=w L^{*}=\frac{w L}{S}|S-F \cos \theta|
$$




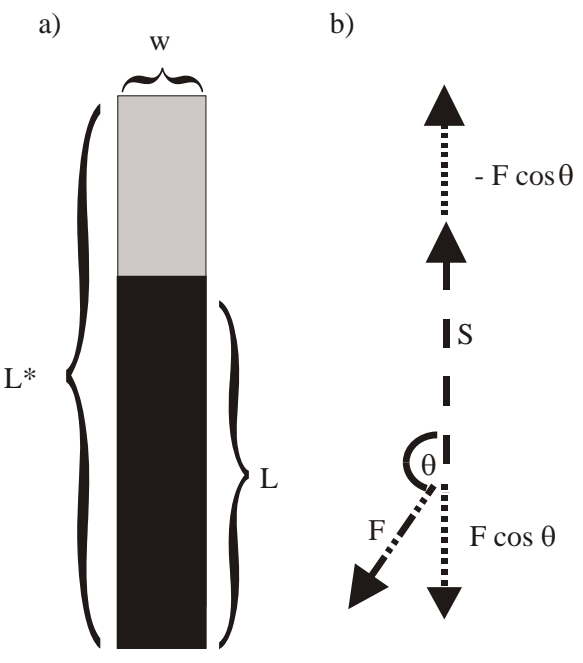

Figure 1. a) Survey area on the ground (black) and additional effective survey area due to fish moving towards the observer (grey). b) Diagram with survey velocity $S$, apparent fish velocity $F$ and approach angle $\theta$. The resulting survey velocity is $S-F \cos \theta$.

The effective survey area depends on several quantities some of which might actually be independent random variables. In this case some refinements to the above formula are required. Assuming all parameters were independent random variables, the approximate expected effective survey area is obtained using the delta method (Seber 1982)

$$
\hat{a}=E[a] \approx \frac{\hat{w} \hat{L}}{\hat{S}}(\hat{S}-\hat{F} \cos \hat{\theta})+\frac{\hat{w} \hat{L}}{2 \hat{S}} \hat{F} \cos \hat{\theta} V[\theta]-\frac{\hat{w} \hat{L}}{\hat{S}^{3}} \hat{F} \cos \hat{\theta} V[S] \quad \hat{F} \cos \hat{\theta}<\hat{S} .
$$

It is assumed that all fish generally swim in the same direction and that hence the approach angle distribution is symmetrical around the mean $\hat{\theta}$. Both the mean and the corresponding variance need to be estimated. The case of similar swimming directions occurs for example, when fish swim against the current in order to feed. As a consequence, fish velocity $F$ in eq. (2) is the swimming speed over ground obtained by taking account of current speed. Mean fish velocity $\hat{F}$ can be estimated for example from acoustic tracking (Priede et al. 1990). Estimates of surveying speed will probably be available in the case of ROV surveys, but more difficult to obtain for divers. Similarly, it should be possible to estimate strip width and strip length rather precisely.

Assuming that $n$ fish have been counted within the effective survey strip, fish density is estimated as

$$
\hat{D}=\frac{n}{\hat{a}}
$$

Similarly, total abundance in Area $A$ is obtained as $N=\frac{n}{\hat{a}} A$, assuming the same density in the whole area.

The variance of the effective survey area can be derived using the delta method (Seber 1982)

$$
\hat{V}[\hat{a}] \approx \hat{a}^{2}\left\{\frac{\hat{V}[w]}{\hat{w}^{2}}+\frac{\hat{V}[L]}{\hat{L}^{2}}+\left(\frac{\cos \hat{\theta}}{\hat{S}-F \cos \hat{\theta}}\right)^{2} \hat{V}[F]+\left(\frac{\hat{F} \sin \hat{\theta}}{\hat{S}-\hat{F} \cos \hat{\theta}}\right)^{2} \hat{V}[\theta]+\left(\frac{\hat{F} \cos \hat{\theta}}{S(S-\hat{F} \cos \hat{\theta})}\right)^{2} \hat{V}[S]\right\}
$$


Similarly, the variance of the density estimate is

$$
\hat{V}[\hat{D}]=\frac{V[n]}{\hat{a}^{2}}+\frac{n^{2} \hat{V}[\hat{a}]}{\hat{a}^{4}},
$$

as the number of animals seen and the effective survey area estimate are independent. Following from this, the corresponding coefficient of variation of population density is

$$
C \hat{V}[\hat{D}]=\left(C V[n]^{2}+C \hat{V}[\hat{a}]^{2}\right)^{1 / 2} \text {. }
$$

In many cases, the survey design will be based on several strip transects. If strip transect $i$ is carried out at velocity $S_{i}$ and fish approach angle is $\theta_{i}$ with common variance $V[\theta]$, the corresponding effective survey area $a_{i}$ is estimated using eq. (2). Assuming that $k$ strip transects have been carried out and that the effective areas estimates of the different strip transect are independent, the following density estimator can then be used

$$
\begin{aligned}
\hat{D}= & \frac{\sum_{i}^{k} n_{i}}{\sum_{i}^{k} \hat{a}_{i}}=\frac{n}{\hat{a}} \\
\hat{V}[\hat{D}] & =\frac{V[n]}{\left(\sum_{i=1}^{k} \hat{a}_{i}\right)^{2}}+\frac{n^{2} \sum_{i}^{k} \hat{V}\left[\hat{a}_{i}\right]}{\left(\sum_{i=1}^{k} \hat{a}_{i}\right)^{4}} .
\end{aligned}
$$

which has variance

In order for this estimator to be applicable, all transect locations have to be chosen randomly or at least the starting position of the first transect if the survey design is systematic.

The variance of the total observed numbers, $V[n]$ in eqs (5) and (8), can be estimated as the sample variance of $k$ strip transects, if all strips are of equal length $\left(L_{i}=L / k\right)$ and observation angles are the same $\left(\theta_{i}=\theta\right)$ in which case $\hat{a}_{i}=\hat{a} / k$. Conditional on the effective observation areas, the variance of observed numbers is estimated as

$$
\hat{V}[n]=\frac{\hat{a}^{2} \sum_{i=1}^{k}\left(n_{i} / \hat{a}_{i}-n / \hat{a}\right)^{2}}{k(k-1)} .
$$

If the strips have different effective areas and assuming $V\left[n_{i}\right]=a_{i} \sigma^{2}$, the conditional estimator becomes

$$
\hat{V}[n]=\frac{\hat{a} \sum_{i=1}^{k} \hat{a}_{i}\left(n_{i} / \hat{a}_{i}-n / \hat{a}\right)^{2}}{k-1} .
$$

Alternatively, a non-parametric bootstrap (Efron and Tibshirani 1993) of strip transects can be carried out where for each strip the total observed number is estimated as

$$
\hat{n}^{b}=\hat{a} \frac{n_{b}}{\hat{a}_{b}},
$$

with $n_{b}$ being the observed number in a strip transect randomly drawn with replacement from the $n_{i}, i=1 \ldots k$, observed transects and $\hat{a}_{b}$ the corresponding effective observation area of the transect. The total observation area $\hat{a}$ corresponds to the observed total effective survey 
area. The variance of observed numbers is then estimated from the $B$ sample bootstrap estimates

$$
\hat{V}[n]=V\left[\hat{n}^{b}\right] .
$$

Given enough strip transects have been surveyed, the variance of the density estimate, $V[D]$ in eq. (8), can also be estimated directly using a non-parametric bootstrap of the numbers per strip transect and a parametric bootstrap of each of the parameters contributing to the effective area estimate (eq. (4)). A density estimate (eq. (7)) is then obtained for each bootstrap resample and the variance estimate is calculated as the empirical variance of the bootstrap sample.

Both the bootstrap and the empirical estimation method are sample based and do not make any assumptions about any particular spatial distribution of fish although the distribution is assumed to be the same over the whole study area. If fish are randomly distributed in space, the observed number of fish should follow a Poisson distribution, in which case $E[n]=V[n]$. Thus the number of observed animals could be used as a variance estimator. For fish species forming groups, group distribution could be random (Poisson) and group size follow a Gamma distribution. The resulting mixture distribution of $n$ would be negative binomial and an appropriate estimator (maximum likelihood or moments estimator, see Johnson et al. 1992) could be used.

\section{Example and conclusions}

The glacial eelpout Lycodes frigidus is a common inhabitant of the North Atlantic deep sea (Bergstad et al. 1999; Prouse and McAllister 1986). For estimating its local density, strip transects were carried out using the ROV Victor 6000 (owned by the Institute Français de Recherche pour l'Exploitation de la Mer) during the summer of 2001 in an area located northwest of Spitzberge $\left(79^{\circ} 4 \mathrm{~N}, 4^{\circ} 10 \mathrm{E}\right)$ at a depth of around $2280 \mathrm{~m}$. The ground consisted of soft sediments and was rather flat. All animals appearing within an approximately $4.8 \mathrm{~m}$ wide strip were counted on video screens as the survey was being conducted and saved on videotapes. Recounting the first 30 minutes on the videotapes with identical results validated counts.

An approximately constant strip width was obtained by operating the ROV with a constant cruising altitude (bottom edge $0.7 \mathrm{~m}$ above ground controlled by the autopilot) and fixed video camera settings (fixed zoom, pan and tilt). Strip width was determined by using a reference scale obtained by posing the ROV on the ground and then using the known width of the ROV frame print $(1.5 \mathrm{~m})$. Animals were counted when they passed an effective line on the screen whose width had thus been estimated to be $4.8 \mathrm{~m}( \pm 10 \mathrm{~cm}$; standard deviation $5 \mathrm{~cm}$ ).

For the survey a fixed zigzag design was used and the starting point and the direction of the first transect were randomly selected. By chance this led to one set of transects approximately against the current alternating with transects roughly perpendicular to the current. Overall seven strip transects, each $250 \mathrm{~m}$ long, were carried out and the number of individuals observed per transect ranged from 4 to 13. Most individuals were encountered actively swimming against the current and all headed into the current, which can be explained by their feeding mode. Their main food source is free swimming and drifting invertebrates including amphipods.

Near bottom current velocity was measured to be around $0.06 \mathrm{~m} / \mathrm{s}$ (Sauter et al. 2002). Surveying speed was estimated from survey time and distance and varied between transects $(0.15-0.3 \mathrm{~m} / \mathrm{s})$ (Table 1). Experience from other surveys has shown that Victor 6000 surveying speed typically varies with a coefficient of variation (CV) of around $15 \%$ even if a 
constant speed is intended (V. Trenkel, unpublished data). Hence a CV of $15 \%$ was assumed in this study.

The velocity of the glacial eelpout is unknown but assumed to be similar to that of another deep-sea species, the grenadier Coryphaenoides armatus, for which Armstrong et al. (1992) estimated a velocity of around $0.06 \mathrm{~m} / \mathrm{s}$ (variance 0.001 ). Uiblein et al (2002) measured the swimming speed of the deep-sea cutthroat eel (Synaphobranchus kaupi) from video records. For this species they found swimming speeds of 0.03 to 0.3 body lengths per second against the current $\left(<0.1 \mathrm{~m} \mathrm{~s}^{-1}\right)$ at depths around $1800 \mathrm{~m}$. Most encountered individuals of Lycodes frigidus were around $30 \mathrm{~cm}$ long (estimated using fixed distance lasers mounted on the principal video camera of Victor 6000). Applying the estimates for S. kaupi, swimming speeds of around 0.009 to $0.09 \mathrm{~m} \mathrm{~s}^{-1}$ would be expected. Hence a velocity of $0.06 \mathrm{~m} / \mathrm{s}$ against the current seems plausible for Lycodes frigidus. As approach angle was not actually measured but rather determined by considering the ROV direction relative to the current direction, it seems reasonable to assume that approach angles have standard deviations of at least 5 degrees.

Effective area estimates for the strip transects of the $L$. frigidus study are given in table 1 . Overall a density of 7338 glacial eelpouts per $\mathrm{km}^{-2}$ was estimated. The variance of observed numbers was estimated both using eq. (9) and a non-parametric bootstrap of strip transects $(B=2000)$. In both cases eq. (7) was used to estimate the variance of the population density of glacial eelpouts. The bootstrapped total observed numbers exhibited a rather skewed distribution (Figure 2). Nevertheless, the sample-based as well as the bootstrap-based estimate of the variance of observed numbers were similar and hence the estimated variances of the population density were not much different (Table 2). Overall, the achieved coefficient of variation of the population density estimate was about twenty-five percent, which seems reasonable.

Table 1. Details for survey transects in study area $79^{\circ} 4^{\prime} \mathrm{N}$ and $4^{\circ} 1^{\prime} \mathrm{E}$ and observed numbers of Lycodes frigidus.

\begin{tabular}{|c|c|c|c|c|c|c|c|}
\hline \multirow[t]{2}{*}{ Type } & \multicolumn{7}{|c|}{ Transect } \\
\hline & 1 & 2 & 3 & 4 & 5 & 6 & 7 \\
\hline Survey duration (s) & 1620 & 1500 & 840 & 1080 & 900 & 960 & 840 \\
\hline Survey speed $\left(\mathrm{m} \mathrm{s}^{-1}\right)$ & 0.15 & 0.17 & 0.3 & 0.23 & 0.28 & 0.26 & 0.3 \\
\hline Strip length (m) & 250 & 250 & 250 & 250 & 250 & 250 & 250 \\
\hline Approach angle $\left(^{\circ}\right)$ & 0 & 90 & 0 & 90 & 0 & 90 & 0 \\
\hline Effective area $\left(\mathrm{m}^{2}\right)$ & 588 & 1200 & 883 & 1200 & 860 & 1200 & 883 \\
\hline $\mathrm{CV}$ of effective area & 0.34 & $2.8 \cdot 10^{-5}$ & 0.13 & $2.1 \cdot 10^{-5}$ & 0.15 & $1.9 \cdot 10^{-5}$ & 0.13 \\
\hline Observed numbers & 13 & 12 & 5 & 5 & 5 & 6 & 4 \\
\hline
\end{tabular}




Figure 2. Distribution of total observed numbers for observed survey area obtained using a non-parametric bootstrap of strip transects $(B=2000)$.

Table 2. Uncertainty estimates for observed numbers and population density using a nonparametric bootstrap and a sample based estimation method. For details see text.

\begin{tabular}{lll}
\hline Quantity & \multicolumn{2}{c}{ 3.1.1. Estimation method } \\
\cline { 2 - 3 } & Bootstrap & Sample \\
\hline $\begin{array}{l}\text { Standard deviation of observed } \\
\text { numbers }\end{array}$ & 11.53 & 13.76 \\
$\begin{array}{l}\text { Standard deviation of population } \\
\text { density }\end{array}$ & 1692.49 & 2019.96 \\
CV of population density & 0.23 & 0.28 \\
\hline
\end{tabular}

Two different variance estimators for the variance of observed numbers were used in the case study. Given the small sample size, the bootstrap variance estimate might be preferable in this case; it was also smaller.

In the presented example, assumed fish velocity ranged from 20 to $40 \%$ of survey velocity. Without the correction a population density of 5952 animals per $\mathrm{km}^{-2}$ would have been estimated, which corresponds to a negative bias of $19 \%$. However, this result relies on the assumed fish velocity and approach angle as well as the variance of the approach angle being correct. In the future it should be attempted to measure swimming speed and approach angle of Lycodes frigidus in order to improve population density estimates. In contrast, there is no evidence that the other assumptions underlying the density estimator, constant population density throughout the survey area and similar fish swimming direction, might not have been met. In addition, no reaction of $L$. frigidus with respect to Victor 6000 was observed during the transects although this does not exclude attraction while the ROV was stationary. If fish reaction would be present, the method proposed by Palka and Hammond (2001) could be adapted to correct for it.

\section{Acknowledgement}

I would like to thank Michael Klages for giving me the opportunity to participate in the cruise "AWI" during which the data used in the example was collected and Benoit Mesnil for helping with the counting of animals. The support of the crew of R/V l'Atalante and the pilots of Victor 6000 was invaluable for the data collection. Hans Skaug, Stéphanie Mahévas and two anonymous referees provided useful comments on earlier drafts of this paper.

\section{References}

Armstrong, J.D., Bagley, P.M., Priede, I.G., 1992. Photographic and acoustic tracking observations of the behaviour of the grenadier Coryphaenoides (Nematonurus) armatus, the eel Synobranchus bathybius, and other abyssal demersal fish in the North Atlantic Ocean. Mar. Biol. 112 (4): 535-544.

Bergstad, O.A., Bjelland, O., Gordon, J.D.M. 1999. Fish communities on the slope of the eastern Norwegian Sea. Sarsia 84 (1): 67-78. 
Buckland, S.T., Anderson, D.R., Burnham, K.P., Laake, J.T., Borchers, D.L., Thomas, L. 2001. Introduction to distance sampling. Estimating abundance of biological populations. Oxford University Press, Oxford.

Dufour, V., Jouvenel, J.-Y., Galzin, R. 1995. Study of a Mediterranean reef fish assemblage. Comparisons of population distribution between depths in protected and unprotected areas over one decade. Aquat. Living Resour. 8 (1): 17-25.

Efron, B., Tibshirani, R. 1993. An introduction to the bootstrap (Monographs on Statistics and Applied Probability 57). Chapman and Hall, New York.

Johnson, N.L, Kotz, S., Kemp, A.W. 1992. Univariate discrete distributions. Wiley, New York.

Palka, D.L., Hammond, P.S. 2001. Accounting for responsive movement in line transect estimates of abundance, Can. J. Fish. Aquat. Sci. 58 (4): 777-787

Priede, I.G., Smith Jr, K.L., Armstrong, J.D. 1990. Foraging behaviour of abyssal grenadier fish: inferences from acoustic tagging and tracking in the North Pacific Ocean. eep-Sea Res. 37 (1A): 81-101.

Prouse, N.J., McAllister, D.E. 1986. The glacial eelpout, Lycodes frigidus, from the Arctic Canadian Basin new to the Canadian ichtyofauna. Can. Field. Nat. 100: 325-329.

Sauter, E., Schlüter, M., Baumann, L. 2002. Geochemistry of deep sea sediments and the bottom water. In The Expedition "AWI" of RV I'Atalante in 2001. Ed. by M. Klages, Mesnil, B., Soltwedel, T., Christophe, A. Berichte zur Polar- und Meeresforschung 422.

Seber, G.A.F. 1982. The estimation of animal abundance and related parameters. Macmillan, New York.

Uiblein, F., Lorance, P. Latrouite, D., 2002. Variation in locomotion behaviour in northern cutthroat eel (Synaphobranchus kaupi) on the Bay of Biscay continental slope. Deep-Sea Res. 149 (9): 1689-1703.

Watson, R.A., Carlos, G.M., Samoilys, M.A., 1995. Bias introduced by the non-random movement of fish in visual transect surveys. Ecol. Model. 77 (2-3): 205-214.

Watson, R.A., Quinn II, T.J. 1997. Performance of transect and point count underwater visual census methods. Ecol. Model. 104 (1): 103-112. 